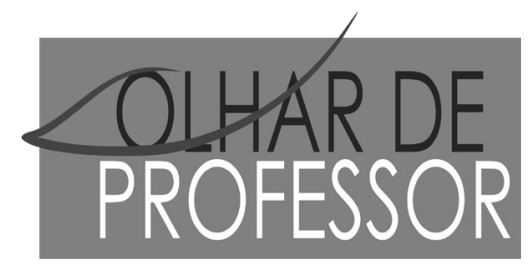

DOI: 10.5212/OLHARPROFR.v.2112.0002

\title{
CORPO HUMANO UM ARTEFATO CULTURAL NO CURRÍCULO DO ENSINO DE CIÊNCIAS NO TERRITÓRIO FEDERAL DO ACRE: GÊNERO, CIVILIDADE - CIVISMO - MORAL
}

\author{
HUMAN BODY, A CULTURAL ARTIFACT IN THE CURRICULUM OF SCIENCE TEACHING IN THE FEDERAL \\ TERRITORY OF ACRE: GENDER, CIVILITY - CIVILS - MORAL \\ CUERPO HUMANO: UN ARTEFACTO CULTURAL EN EL CURRÍ́CULO DE ENSEÑANZA DE CIENCIAS EN EL \\ TERRITORIO FEDERAL DE ACRE: GÉNERO, CIVILIDAD, CORTESŚA, MORAL
}

\author{
MURILENA PINHEIRO DE ALMEIDA* \\ MARCO ANTONIO LEANDRO BARZANO** \\ CLEYDE OLIVEIRA DE CASTRO ${ }^{\star \star *}$ \\ CENAIR FELINI SOARES ${ }^{\text {**x }}$
}

\begin{abstract}
Resumo: Este trabalho visa analisar o funcionamento dos mecanismos de legitimação do tema corpo humano, no currículo do ensino de ciências da escola primária, no Território Federal do Acre, de 1910 até 1939. Mobilizouse os aportes da História Cultural, a pesquisa documental, a análise de conteúdo, a técnica snowball e entrevistas em profundidade com professoras. As fontes documentais utilizadas: programas de ensino, regulamentos de funcionamento do ensino primário, fotografias, gravuras, notícias e artigos sobre educação em jornais da época. A construção e abordagem das séries documentais e a análise foram mediadas pelo conceito de representação social. As representações sobre o corpo, erigidas sob um viés antropocêntrico e uma linguagem androcêntrica, encontravamse subjacentes aos modos diversificados da escolarização do Território Federal do Acre, e, consubstanciou o tema corpo humano como artefato cultural, no eixo civilidade - civismo - moral, para produzir o brasileiro e a brasileira acreanos.
\end{abstract}

Palavras-chave: Gênero. Ensino de ciências. Corpo humano.

Abstract: This work aims to analyze the functioning of the mechanisms of legitimation of the human body theme, in the curriculum of elementary school science education, in the Federal Territory of Acre, from 1910 to 1939. The contributions of Cultural History, documentary research, content analysis, snowball technique and in-depth interviews with teachers were mobilized. Documentary sources used: teaching programs, primary education regulations, photographs, prints, news and articles on education in newspapers of the time. The construction and approach of documentary series and analysis were mediated by the concept of social representation. The representations about the body, erected under an anthropocentric bias and an androcentric language, were underpinned by the diversified modes of schooling in the Federal Territory of Acre, and embodied the theme of the human body as a cultural artifact in the civilicity-civic-moral axis, to produce the Brazilian Acreans.

Keywords: Gender. Science teaching. Human body.

\footnotetext{
* Doutora em Ensino, Filosofia e História das Ciências. Professora Adjunta do Centro de Educação, Letras e Artes da Universidade Federal do Acre. E-mail: murillena@gmail.com

** Doutor em Educação. Professor Titular do Centro de Educação, Letras e Artes da Universidade Estadual de Feira Santana. Coordenador do Grupo de Pesquisa Rizoma. E-mail: marco.barzano@gmail.com

*** Doutora em Educação. Professora Adjunta do Centro de Educação, Letras e Artes da Universidade Federal do Acre. E-mail: cleydecastro@yahoo.com.br

*****Graduando em Direito. Faculdade da Amazônia Ocidental. E-mail: cenair.soares@bol.com.br
} 
Resumen: Este trabajo tiene como objetivo analizar el funcionamiento de los mecanismos de legitimación sobre el tema del cuerpo humano, en el currículo de enseñanza de ciencias en el nivel de Educación Básica, en el territorio Federal de Acre desde 1910 hasta 1939. Se utilizaron los aportes de la historia cultural, la investigación documental, el análisis de contenido, la técnica snowball y entrevistas en profundidad con profesoras. Las fuentes documentales utilizadas fueron: Programas de enseñanza, reglamentos de enseñanza a nivel de Educación Básica, fotografías, grabaciones, noticias y artículos de revistas de la época. La construcción y abordaje de las series de documentos y análisis estuvieron mediadas por el concepto de representaciones sociales. Las representaciones sobre el cuerpo, erigidas bajo un régimen antropocéntrico y un lenguaje androcéntrico, estaban subyacentes en los modos diversificados de la escolarización del Territorio Federal de Acre, e incorporó el tema de cuerpo humano como artefacto cultural, en el eje civil - civismo - moral, para producir al brasilero y la brasilera acreanos.

Palabras claves: Género. Enseñanza de Ciencias. Cuerpo Humano.

\section{INTRODUÇÃO}

O presente trabalho visa explicitar o funcionamento dos mecanismos de legitimação do tema corpo humano na escola primária, no currículo do ensino de ciências da escola primária, no Território Federal do Acre, no marco temporal de 1910 até 1939. Um período marcado pela anexação do Acre ao Brasil, a queda dos preços da borracha no mercado internacional e a deflagração da Segunda Guerra Mundial, e também pela constituição e difusão da instrução pública por intermédio da propagação da escola primária no Território do Acre. A consecução dessa pesquisa se debruça sobre a história do processo de criação e difusão da escola primária no Território do Acre e concentra seu foco na abordagem do corpo no currículo do ensino de ciências. Nesse estudo são apresentadas imbricadas relações com o legado histórico do Acre, a sua população heterogênea, resultante do amálgama entre muitas etnias indígenas e não-indígenas, em um ambiente caracterizado pela floresta equatorial.

O seringal (a unidade de produção extrativista gumífera) ocupa lugar central nessa trama social e se constitui em uma referência de produção cultural e identitária da população acreana. De tal sorte que sobreviver nele e às adversidades de seu contexto contribuíram para erigir modelos e modos de ser e comportar-se, conduzir a homens, mulheres e crianças produzindo uma cultura que privilegiou certos modelos de masculino e feminino, para além dos determinantes estritamente biológicos, nem sempre explícitos no currículo. Assim, compreende-se que a escolarização situa a escola como o locus prioritário da educação institucionalizada, e confere centralidade ao currículo, o conhecimento a ser ensinado e aprendido. Isso, por sua vez, suscita o exame de sua constituição histórica, assim como, dos temas que, em certos momentos, passaram a compor o currículo, ou dele se tornam ausentes, ou ainda inscritos em tramas de conflitos, disputas e silenciamentos. (GIROUX, 2003; GOODSON, 1997).

Nesse sentido, o corpo humano é um desses temas que engloba uma complexidade de disputas, conflitos, silêncios, ocultamentos, busca legitimar-se e conferir legitimidade por meio da ciência a outros tantos temas e conceitos na configuração do currículo. A ciência alega que "o corpo oferece uma sólida fundação, um ponto causal, do significado de homem e de mulher.” (LAQUEUR, 2001, p. 202). E consequentemente, isto se expressa na produção de pessoas, tais como: as questões relacionadas à saúde, higiene, gênero, papéis sociais, identidade, sexualidade, raça, etnia, geração, genética dentre outras vinculações complexas presentes na constituição do humano como ser e de seu ser nos tecidos do mundo social e cultural intermediado pelo currículo.

Todas as ilustrações anatômicas, históricas e contemporâneas são abstrações; são mapas de uma realidade surpreendente e infinitamente variada. As representações das características pertencentes em especial ao homem e a mulher, em razão das enormes consequências sociais dessas distinções, são mais obviamente determinadas pela arte e pela cultura. Como os mapas, as ilustrações anatômicas focalizam a atenção em uma característica particular ou em um grupo particular de relações espaciais. Para realizar essa função, assumem um ponto de vista - incluem algumas estruturas e excluem outras, e esvaziam o espaço cheio de matéria que enche o corpo: gordura tecido conjuntivo e "insignificantes variações” que não merecem nomes ou identidades individuais. (LAQUEUR, 2001, p.203). 
As representações que compõem o conjunto de conhecimentos em anatomia e fisiologia expressam um tipo de produção cultural e histórica que possuem um lugar social e transbordam o significado de estados particulares do conhecimento sobre as estruturas do corpo. (LAQUEUR, 2001; ROHDEN, 2003; FAUSTO-STERLING, 2006; LE GOFF; TRUONG, 2012.). A produção desses conhecimentos, além de aspirarem à elucidação dos mistérios do corpo, também cumprem funções sociais e políticas, e deste modo, carecem tanto de uma rede de elaboração como de transmissão e circulação de seus conhecimentos. A escola se constitui em um desses espaços. Assim, o corpo humano é um tema que conquistou espaço nas tramas do processo de escolarização e ocupa um lugar mediado por formas metodológicas de abordagem, no currículo do ensino de ciências, na escolarização e em especial na fase inicial, para cumprir finalidades políticas e socioculturais legitimadas pelo discurso científico e seus regimes de verdade. A própria escolarização também contribuiu para conformar, configurar social e culturalmente o corpo humano, por meio da valorização e o privilégio a certos padrões culturais e práticas sociais.

\section{A SELEÇÃO DAS FONTES E A PRODUÇÃO DA NARRATIVA}

A seleção e elaboração do corpus documental foram realizadas junto aos acervos Centro de Documentação Histórica, Conselho Estadual de Educação do Acre, Arquivo Geral do Estado do Acre, Museu da Borracha e no Acervo do Centro de Informação e Biblioteca em Educação - CIBEC em Brasília. Buscou-se localizar todos os documentos disponíveis sobre a escola primária, relativos ao Território Federal do Acre. Foram encontrados programas de ensino, regulamentos de funcionamento do ensino primário, fotografias, gravuras, notícias e artigos sobre educação em jornais da época. Além dos documentos impressos selecionados, também foram realizadas entrevistas, com professoras que exerceram o magistério primário, no Território Federal do Acre.

O convite às professoras para participar desta pesquisa foi intermediado por outras professoras, com as quais as entrevistadas mantêm relações de amizade, respeito e cordialidade, construídas ao longo de suas trajetórias profissionais. Essa técnica de seleção de participantes para pesquisas é conhecida como snowball, bola de neve, ou cadeia de informantes. Trata-se de uma amostragem não probabilística, na qual os participantes de uma pesquisa indicam, sucessivamente, outros participantes, até que se atinja um ponto de saturação das informações obtidas. Portanto, traça-se uma cadeia de referência ou uma forma de rede de contatos. O emprego da técnica snowball permite recrutar para a pesquisa, pessoas que exerceram ou exercem papel de liderança, ou que contam com o reconhecimento de seus pares e da comunidade em que vivem, em razão da atuação e relevância do trabalho realizado. A utilização dessa técnica permite captar e efetuar um processo reflexivo sobre as práticas sociais vivenciadas. (BIERNACKI; WALDORF, 1981).

O período do Acre Território corresponde à anexação das terras acreanas ao Brasil, com desfecho definitivo em 1910 e encerra-se com a elevação do Território a condição de Estado da Federação, em 1962. Ao longo desse período, a instrução pública assumiu diferentes modos de realização e de configuração da escola primária e de seu currículo. Captar essas transformações na escolarização destinada à população do Território compele a recorrer e recuperar as narrativas, vivências e experiências profissionais de professoras protagonistas da educação acreana (na escola primária), sobretudo, aquelas mais recuadas no tempo, no Acre Território. Após a realização das entrevistas, essas foram organizadas em décadas, constituindo uma série temporal juntamente com as fontes documentais. Assim, as experiências e vivências expressadas adentram e ensejam à reflexão sobre importantes aspectos da organização e funcionamento da escola primária acreana, do seu currículo e do trabalho docente. Além de registrar o legado e prestar o reconhecimento ao protagonismo feminino na formação cultural de várias gerações de estudantes no Acre Território, um trabalho arduamente realizado àquela época e em condições desafiadoras, precárias, adversas e por muitas vezes inóspitas. 


\section{O ENSINO PRIMÁRIO NO TERRITÓRIO FEDERAL DO ACRE: O CORPO HUMANO UMA PRODUÇÃO CULTURAL NO CURRÍCULO DO ENSINO DE CIÊNCIAS}

O governador primeiro do Território Federal do Acre, Epaminondas Jácome e Francisco de Oliveira Conde, responsável pela Instrução Pública, promoveram uma reorganização do ensino no Território materializada no regulamento escolar editado em 1921. (CASTRO, 2011). Conforme esse documento, o ensino público constituía-se em três graus: primário, secundário e profissional. Esse último funcionava através das aulas de trabalhos manuais. O ensino primário, herdado do período dos Departamentos da anexação ao Brasil até 1920, manteve-se subdividido em dois níveis: elementar e complementar. (NOGUEIRA, 1982, p. 2). O curso elementar constituía os dois primeiros anos do ensino primário, no qual os alunos estudavam as seguintes disciplinas: Língua Portuguesa, Caligrafia, Aritmética, Educação Física, Exercícios Militares, Educação Cívica, Ginástica e Noções de Higiene, conveniente e progressivamente distribuídas em programas. Nos dois últimos anos do ensino complementar, eram acrescidas as disciplinas Geografia do Brasil e do Acre, História do Brasil e do Acre, Geometria Prática, Desenho Linear, Noções Elementares de História Natural, Zoologia e Mineralogia.

A instrução pública passou a constituir encargo da Diretoria de Instrução Pública do Governo do Território e algumas escolas passaram a ser administradas pelas prefeituras locais. (CASTRO, 2011; LIMA, 2012). Assim, permaneciam as distintas formas de organização escolar, no oferecimento do nível ensino primário elementar - à alfabetização da população, mediante os tipos de escolas: as escolas ambulantes, rurais, urbanas, noturnas e os grupos escolares. As escolas ambulantes ofertavam o primeiro ano do ensino primário e consubstanciavam a intenção de difundir e fazer chegar à população do interior do Território, aos seringais, a alfabetização e as noções de conhecimentos considerados imprescindíveis a quaisquer indivíduos, sobretudo, as noções de higiene, de civilidade e civismo. As escolas ambulantes destinavam a alfabetização da população residente nos seringais e careciam da aquiescência dos proprietários seringalistas.

Nas cidades sedes dos municípios acreanos havia um grupo escolar, onde se ministravam o curso elementar e o curso complementar, e uma rede de escolas (isoladas, ambulantes, noturnas e elementares) nas quais se ministravam o curso elementar. Conforme dados coligidos por Ginelli (2008) a população escolar de algumas localidades acreanas girava em torno de 150 a 200 alunos. A população estimada do Acre até o final dos anos 20, segundo consta no livro "Resumo Histórico da Formação do Acre" (elaborado em 1928 e utilizado nas escolas confessionais), era de 21.500 habitantes. O governo unificado do Território do Acre, assim como as demais unidades da federação, se defrontava com o desafio de alfabetizar e instruir a sua população em idade escolar, portanto, superar o analfabetismo e difundir a instrução primária, em um contexto histórico marcado pelo analfabetismo que atingia 70,2\% da população acreana. (CASTRO, 2011).

Logo, a ausência e a insuficiência da instrução pública impediam o desenvolvimento da região e se constituíam em um entrave a consolidação da anexação do Território do Acre ao país. Pois, carecia urdir e consolidar entre os acreanos uma identidade nacional brasileira, missão a ser efetivada por meio do ensino primário e da difusão da escola primária. Era imperativo expandir e consolidar, no Acre, o modelo de escola graduada - o grupo escolar - com suas práticas, organização e funcionamento, articulados sob a referência e a lógica das matérias escolares. Os estudantes precisavam vencer as barreiras das formas precárias da escolarização, que, quando disponível priorizava apenas a alfabetização, o primeiro ano do curso elementar, ministrada em escolas ambulantes, rurais, urbanas e noturnas. Todavia, a etapa seguinte do curso primário - o curso complementar, somente era ministrado nos grupos escolares, instalados nas sedes dos municípios. Desse modo, o curso complementar era acessível a um número muito reduzido de estudantes em relação à população geral, em idade escolar. O ingresso nesse nível de ensino exigia dos estudantes que dominassem e demonstrassem as seguintes habilidades, descritas pela professora Euri Figueiredo ${ }^{1}$, registrada em 2014:

\footnotetext{
${ }^{1}$ Nasceu em Xapuri, filha de um farmacêutico, foi levada com a família para o seringal Perseverança/Araxá aos três anos de idade, quando o pai assumiu a gerência daquele seringal. Apenas retornou sede do município de Xapuri - AC para ser estudante na escola primária Divina Providência, ingressou no primeiro ano do ensino primário em 1939. Porém, aprendeu a ler, escrever, a contar e a tabuada em casa com a sua mãe, nas poucas horas vagas, no seringal. Conforme o costume da época, no Acre, as mães
} 
Era muito notável que você só passava para o terceiro ano primário se você soubesse as quatro operações: somar, subtrair, multiplicar e dividir e soubesse conjugar direitinho, os verbos ser, ter e haver, os verbos auxiliares. Se você não fizesse isso você não era apto a passar para o terceiro ano. Podia ter nota, podia não ter, mas, tinha que saber isso! Assim, quem ia até o fim (o quarto ano) ia. Mas, a maioria ficava pela metade. Porque era muita exigência, era muita complicação, muito castigo, palmatória. Então tudo isso, afastava. Porque as crianças iam alcançando idade, iam alcançando idade e ingressam no mercado de trabalho. As crianças trabalhavam, começava-se a trabalhar muito cedo. (Entrevista concedida pela professora Euri Figueiredo, em junho de 2014).

Diante da difícil tarefa de educar uma população dispersa em uma floresta entendia-se o ler, escrever e contar, como fundamental para entender o mundo e acessar individualmente outros conhecimentos. Em um contexto cultural em que as crianças trabalhavam e assumiam as mesmas responsabilidades de adultos, principalmente, as meninas. À medida que cresciam, já aos sete ou oito anos de idade, as meninas iam progressivamente assumindo as tarefas domésticas. Na prática cultural das famílias havia um regulamento tácito das obrigações das crianças. Portanto, engendrava-se uma lógica de infância que secundarizava o brincar e exaltava o trabalho em uma jornada de labuta junto aos adultos, forjava-se o futuro trabalhador pelo aprendizado do trabalho nas próprias atividades laborais cotidianas.

Conforme o Regulamento da Instrução Pública do Território Federal do Acre de 1930 a expansão da rede escolar se realizava mediante o recenseamento escolar e a existência de comunidades com o número mínimo de 30 crianças em idade escolar. A coeducação - sob a perspectiva da coexistência simultânea de meninos e meninas nos mesmos espaços escolares - passou a ser incorporada enquanto um princípio organizador do funcionamento das escolas públicas e normatizador das suas práticas pedagógicas no Acre Território. Por conseguinte, o controle do corpo, da sexualidade e as representações produzidas sobre o corpo permaneciam subjacentes à conformação do sistema de ensino e subsidiavam as práticas pedagógicas, assim como referendaram as políticas de gênero perpetradas no âmbito da escola primária. As escolas ambulantes, urbanas, rurais, os grupos escolares e as escolas noturnas haviam incorporado o princípio da coeducação, na perspectiva da admissão da coexistência simultânea, de meninos e meninas nos mesmos espaços escolares, superando a separação dos sexos. Contudo, ainda era necessário aprender a conviver, a respeitar e a produzir a igualdade de gênero e superar o androcentrismo e a dominação masculina. (AUAD, 2003; BOURDIEU, 2012).

Nesse contexto predominou o acesso a um currículo restrito aos rudimentos da leitura e da escrita e as noções de conhecimentos limitados às noções de higiene, de civilidade e civismo, aquele momento, considerados imprescindíveis aos indivíduos, de modo a torná-los úteis a pátria e aptos a constituição de família. Assim, preceituava o Artigo 61 do Regulamento da Instrução Pública do Território Federal do Acre, de 1930:

A finalidade do ensino será tornar o indivíduo mais apto para os empreendimentos da vida, desenvolvendo a sua inteligência, aperfeiçoando suas qualidades físicas, morais e cívicas, indicando-lhe a necessidade de constituição da família ${ }^{2}$ e, habilitando-o, enfim, ao desempenho das funções que o meio e as suas condições sociais exigirem. (REGULAMENTO DA INSTRUÇÃO PÚBLICA DO TERRITÓRIO FEDERAL DO ACRE, 1930).

quando sabiam ler, escrever, contar e dominavam a tabuada transmitiam esses conhecimentos, a sua cultura letrada aos filhos. As crianças eram alfabetizadas em casa por suas mães. A alfabetização constituía a educação doméstica. (Consequentemente, quando as mães eram iletradas, as crianças cresciam analfabetas e tinham poucas chances de se alfabetizar. Pois, frequentar a escola ainda não era a regra nesse período no Acre Território). Euri Figueiredo concluiu os estudos no primário e submeteu-se ao Exame de Admissão, foi aprovada e cursou o Normal Regional, o ensino secundário daquele período, equivalente ao curso ginasial. A professora Euri Figueiredo ingressou no magistério primário ainda adolescente em 1950, com a enorme responsabilidade profissional, a incumbência de preparar as turmas do $4^{\circ}$ ano do Colégio Divina Providência para o Exame de Admissão, ministrava todas as disciplinas do ensino primário: português, matemática, geografia, história, ciências e educação moral e cívica. E trabalhou em toda a sua vida como professora. Fala gravada em junho de 2014, na casa da Professora EuriFigueiro, em Xapuri - Acre.

${ }^{2}$ Grifo nosso. O Regulamento da Instrução Pública deixava explícita a produção da pessoa útil e ajustada a sociedade do país, por meio da prescrição de um ensino que também enfatizava noções práticas consideradas úteis à vida cotidiana e aos processos produtivos. 
O conteúdo, o teor da educação, a própria forma de organização e o funcionamento das escolas públicas, ainda não haviam superado e estavam impregnadas pela dominação masculina, que se expressava em referências androcêntricas e desigualdades de gênero presentes na configuração do sistema escolar e expressas nas práticas pedagógicas.

O ensino no Território do Acre terá como objetivo a transformação da criança em um ente útil ao país ${ }^{3}$ e, em particular à região, conhecendo a sua própria personalidade e o meio ambiente, ficando apta, desta forma, a colaborar conscientemente a grandeza de ambos e para 0 bem da humanidade. (REGULAMENTO DA INSTRUÇÃO PÚBLICA DO TERRITÓRIO FEDERAL DO ACRE, 1930).

No Acre Território, como nas demais regiões do país, urgia empreender a conformação da criança em ente útil ao país, à região, conhecedor de sua própria personalidade e do meio ambiente, apto a colaborar conscientemente com a grandeza da pátria e o bem da humanidade, isso se viabilizava mediante um currículo que comportava uma rígida norma disciplinar que atuava de modo a erigir o corpo dócil. Ao ingressar na escola, os corpos dos estudantes eram inseridos na trama de uma política simbólica, atravessados e modelados por limitações, obrigações e proibições. Às crianças, fazia-se necessário aprender o ofício de aluno, incorporar e cumpri o código de disciplina escolar, o explícito e o tácito, que, por sua vez, confluía e reafirmava a conduta social vigente. Nessa perspectiva, o ensino primário no Território do Acre articulava e introjetava nos estudantes o eixo curricular moral - civismo - higiene, enquanto conhecimentos, habilidades e habitus incorporados para produzir o autocontrole, o autoconstrangimento e esculpir o ser dócil e obediente.

A escola mediante o emprego de forças coercitivas explícitas e tácitas, especialmente, o código disciplinar controlava os gestos, os risos, as atitudes e a linguagem das crianças. Assim, o eixo curricular moral - civismo - higiene primava por valores considerados necessários à convivência social e principalmente ao trabalho. Então, se zelava pelo asseio, limpeza, disciplina, obediência e respeito ao próximo como habitus incorporados. Por conseguinte, os discursos articulados e enunciados, por meio da seleção cultural e social, nas disciplinas Educação Moral e Cívica, Higiene, Trabalhos Manuais e Ciências Físicas e Naturais se convertiam em uma modalidade de habitus incorporados e automatizados nos indivíduos, e consequentemente, conformavam a configuração do grupo geracional que frequentou a escola primária nesse período.

Conforme, as normas disciplinares estabelecidas pelo Regulamento da Instrução Pública de 1930, os alunos estavam sujeitos à obediência aos professores, dentro e fora da escola, que lhes transmitiriam em qualquer oportunidade os preceitos de moral, de civismo e de higiene. O que acarretava nos educandos, a introjeção de um controle cada vez maior, sobre si mesmo, o automatismo de hábitos, a incorporação do autocontrole - o corpo educado da pessoa útil e produtiva. A produção escolar do autocontrole, da interiorização dos constrangimentos e do automatismo dos hábitos, implicava a eficiência da ação do Estado na produção das pessoas úteis servis à pátria, sobretudo, o trabalhador. (FOUCAULT, 1987; ELIAS, 1994).

A violência naturalizada estava imbricada à cultura escolar e integrava o corpus das práticas curriculares, para corrigir, reprimir e repreender os atos, as condutas, reprováveis e inadequadas nos estudantes e por em seu lugar a virtude. Na escola primaria acreana a palmatória corrigia todos os erros e inscrevia nos indivíduos (crianças) os ideais da boa moral. A moral, o civismo e a higiene eram forjados sob a égide da violência, que estava formalmente proscrita, isto é, uma letra morta apenas na normativa formal do ensino, porém viva e naturalizada na cultura escolar e também fora das escolas. O discurso da correção dos erros justificava e naturalizava a violência, contra as crianças, dentro e fora da escola, e, por conseguinte, se constituía e estava incorporada nos adultos enquanto, um habitus cultural necessário à educação dos filhos e constitutivo do exercício do pátrio poder.

No Acre Território, os castigos corporais tinham várias finalidades: o constrangimento para a regulação moral das crianças, produzir a vergonha, infligir o temor, o medo dos mestres, entendido à época como respeito, e a correção frente aos erros na execução das tarefas escolares, especialmente, a tabuada, e quaisquer outros erros e às recusas em fazer os deveres de casa - trabalhos escolares prescritos pelas

${ }^{3}$ Grifo nosso. 
professoras, para serem feitos pelos alunos em suas casas. Os comportamentos e modos considerados inadequados eram corrigidos com castigos que infligiam aos estudantes sofrimentos físicos e/ou psicológicos. Desse modo, a violência física e psicológica contra as crianças era naturalizada e acolhida no interior da escola primária, enquanto instrumento necessário à moralidade, ao asseio e à civilização. E assim, domesticavam-se os espíritos irrefreáveis e pertinazes.

Efetivamente, as normas disciplinares escolares, fundamentadas nos pressupostos de uma filosofia liberal que celebrava o indivíduo, perseguiram em última instância o culto a virtude, a extirpação dos vícios, a formação do caráter moral, elementos cruciais para o ajustamento social - a conduta moral ilibada, os bons costumes e a autocensura. Sob esse prisma, era necessário aprender a cuidar de si mesmo para se autogovernar. A eficiência do estado no controle dos indivíduos manifestava-se enquanto uma cultura incorporada em habitus que e engendrou o corpo educado e civilizado. O Estado intervia nos corpos, por intermédio do ensino primário e seu conjunto de práticas culturais, para materializar o corpo educado ao exercício da moral e dos bons costumes e dócil ao trabalho. (LOURO; FELIPE; GOELLNER, 2012).

O conhecimento incorporado no interior das práticas sociais e culturais tem no currículo escolar uma de suas principais formas de estabilização para transmissão e circulação, sendo capaz de instituir-se e transformar-se em tradição. (GOODSON, 1997). Assim, o currículo instituído e prescrito, no Território do Acre em 1930 - mediante a conformação das matérias escolares Ciências Físicas e Naturais, Higiene, Educação Moral e Cívica e Trabalhos Manuais - era tributário da ideia que remonta aos fundamentos da modernidade, o conhecimento útil, aplicável, usável. Essas matérias escolares articularam construções discursivas e engendraram práticas culturais, com o propósito de produzir corpos saudáveis, civilizados, dóceis, produtivos e úteis a pátria.

A invenção da disciplina Higiene, com o propósito de produzir a saúde e rechaçar a doença, implicava em por em circulação saberes com finalidades sociais e políticas, especialmente a ética, a estética e a poética da limpeza, entrelaçando o controle dos corpos, ao aprimoramento da raça e a salubridade do ambiente, inclusive o escolar. A produção da Higiene, enquanto um componente curricular do ensino primário, no Território do Acre, intencionava enfrentar por meio da educação, a representação social produzida pelo olhar externo - por uma lógica claramente etnocêntrica - que lançava à população acreana a pecha da incivilidade, da imoralidade e do atraso. Assim, urgia ensinar à população hábitos e práticas de civilidade e enfrentar a precariedade das condições de vida da região e os costumes acreanos.

A pobreza e a precariedade, predominante na região acreana, foram inicialmente creditadas à crise no extrativismo gumífero e a desvalorização do preço da borracha no mercado internacional, em consequência à concorrência da produção da borracha proveniente de seringais de cultivo ${ }^{4}$, em regiões da Ásia e da África. (MARTINELLO, 1988). Uma faceta das condições da vida material ${ }^{5}$ da população acreana, no início do governo unificado do Território, pode ser conhecida, a partir de um relato em uma carta de 1922, do Bispo da Prelazia do Acre e Purús Dom Próspero Bernadi, aos membros da Ordem dos Servos de Maria, na Itália:

As condições de pobreza, higiene e moralidade no Acre em 1922, em Carta do Bispo Próspero Bernardi de 20 de setembro de 1922 (Archivio Generale da Ordem dos Servos de Maria): Pobreza física e moral. "No meio deste riquíssimo da natureza, é o mesmo rei que não está a altura do papel. Pobreza física e moral. Pobreza nas moradias, muitas das quais são simples coberturas de palha, sem algum traço de vida civil. Muitas vezes a cadeira melhor que tinham para oferecer ao Bispo, era uma velha lata de querosene. Pobreza no vestuário. Muitos nem se apresentam porque não tem com que se cobrir. Já vi várias vezes um vestido ser usado por oito ou dez pessoas; uma mulher se apresentando com o vestido do marido; três filhos usando

\footnotetext{
${ }^{4}$ Nos seringais de cultivo, o plantio de seringueiras em linhas próximas entre si, maximizava a eficiência da produção do látex, porque os trabalhadores não precisavam percorrer grandes distâncias dentro da floresta, entre uma seringueira e outra para colher o látex. (MARTINELLO, 1988).

${ }^{5}$ D. Próspero Bernadi em outro documento A. I. Appunti gastronimici, In.: SERVO DI MARIA, nº 12, Bologna 1931, p. 39 citado por LOMBARDI e PERTIÑEZ Relata que “A situação econômica era igual para todos. Era possível encontrar com certa tranquilidade nos centros urbanos, carne fresca, leite puro, pão, verdura e frutas. O problema era o dinheiro. De outro lado, a abundância dos insetos devoradores era tão grande que as estantes que deveriam conter os livros da biblioteca do convento foram ocupadas por vidros de arroz e feijão.”
} 
a roupa do pai, sendo que o mais velho vestia as calças, o segundo a camisa e o caçula as cuecas. Pobreza na alimentação. Estamos na terra do açúcar e do café e aconteceu também comigo de encontrar essa bebida sem que entrasse nem café e nem açúcar [...] o café e o açúcar estão indo no exílio. Num lugar encontrei tanta pobreza que não tinha nada a oferecer a não ser milho cozido. E isso aconteceu várias vezes. Pobreza intelectual e moral. O analfabetismo aqui chega a 95\%. As uniões ilegítimas e as separações arbitrárias nas famílias só agora estão diminuindo, mas poucos anos atrás, a desgraça era a situação normal de quase toda população do Acre. Ao lado da pobreza vai a falta de higiene. Os poucos que usam uma mesa para as refeições, se tiverem uma toalha para forrar, esta costuma ser colorida, pois todos com ela limpam a boca e as mãos [...] Copos, ninguém conhece, no lugar deles usam caneco ou garrafa talhadas. No rio, um rapaz para beber, tirou um sapato, o mergulhou na água e tomou a vontade [...] Pântanos, mordidas de insetos, falta de medicamentos e alimentação suficiente [...], tudo explica as doenças que produzem morte, especialmente nas crianças. As canoas que eles usam são todas esburacadas [...] até que a minha tarefa durante uma viagem era a de esvaziar a canoa que estava enchendo de água [...] Quem conserta um relógio é ourives, todos são coronéis sem pertencer ao exército, todos são doutores, mas sem formatura [...], quem tira os dentes é o barbeiro [...] (PERTIÑEZ; LOMBARDI, s/d, p. 121- 122).

As condições materiais precárias, predominantes entre os habitantes do Território do Acre, foram incisivamente agravadas pelas condições de isolamento geográfico que dificultavam a integração às demais regiões do país e perduram ao longo do século XX. Todavia, mesmo distantes dos centros produtores da erudição cultural da época, os corpos das crianças acreanas foram alcançados pelas políticas simbólicas e pelos signos da higiene que celebraram os ideais de modernização, civilidade e moralidade. A higiene passou a integrar a cultura escolar, em toda a extensão do trabalho pedagógico, na constituição do ambiente escolar às práticas pedagógicas, e se secularizou nos espaços sociais, como um componente cultural de controle dos corpos, em estreita articulação com valores e preceitos morais.

Dessa forma, o currículo do ensino de ciências assumiu um viés antropocêntrico e androcêntrico ao abordar a natureza e a natureza humana. Os temas selecionados no currículo abordavam fenômenos naturais considerados fundamentais à sobrevivência humana, em uma perspectiva universal, e também, destacava aspectos específicos da região do Território do Acre, e ainda recursos tecnológicos que facilitavam ou traziam benefícios à vida humana, sobretudo, naquela região. Portanto, se justificava a opção pelo ensino e o aprendizado de noções elementares e rudimentos, que permitiam um conhecimento superficial, das características gerais de plantas e animais. Desse modo, aludia-se ao conhecimento de aspectos ambientais e fenômenos constituintes do mundo natural direcionados à utilização humana. Sob esse prisma, o currículo abordava o uso de animais, plantas e minerais, assim como, os recursos ambientais o ar, a água, o solo e fenômenos físicos, químicos e os recursos tecnológicos, para a satisfação de necessidades humanas. Dessa maneira conferia-se um viés antropocêntrico ao ensino de ciências que o vinculava ao setor produtivo.

Nessa proposição, o homem estava colocado em uma posição hierárquica superior, em relação aos demais entes da natureza. A racionalidade humana expressa pela ciência e pela tecnologia proporcionava as condições para a exploração e o domínio da natureza, de modo a torna-la útil, ao provimento das necessidades humanas. Todavia, essa abordagem utilitarista da natureza e de seus fenômenos vinculava as precárias condições da vida local acreana à falta e à insuficiência de conhecimento científico. Dessa forma, esse ensino de ciências abstraía e naturalizava as contradições da realidade social, apresentava-se neutro na abordagem de seus objetos de conhecimento.

A abordagem do corpo humano está prescrita nas quatro séries do ensino primário. O homem se constituía no referente principal na linguagem expressa nesse currículo. O termo "homem" era empregado em um sentido universal e generalizante, que intencionava abranger todo o conjunto da diversidade humana. Sob esse signo - "o homem” colocava-se a mulher subentendida e em subsunção ao homem e reafirmava-se a predominância do masculino sobre o feminino e à natureza. Pois, nessa representação é o homem quem domina a natureza e a mulher apenas ocupa um papel secundário. 


\section{CONSIDERAÇÕES FINAIS}

As abordagens do corpo humano, na escola primária, são atravessadas por poderes simbólicos, representações e práticas sociais que implicam em certas formas de subjetividades e em políticas de produção de identidades, que erigem projetos societários e privilegiam padrões culturais. Os conhecimentos provenientes da fisiologia e anatomia, a serem ensinados na escola primária conectam-se aos modelos, aos papéis sociais, aos limites, aos padrões culturais impostos e legitimados aos homens e as mulheres, por meio do conhecimento científico que comporta o tema corpo humano. A seleção temas e o foco produzido na abordagem do corpo humano, enquanto objeto de conhecimento no ensino primário, priorizava aspectos e fenômenos relativos à manutenção da vida humana articulados às políticas de gênero, às tramas do social e da cultura.

A abordagem dos aspectos estruturais e específicos do corpo humano envolviam rudimentos de anatomia e fisiologia, que intencionavam prover os estudantes com um conhecimento de si mesmo, o aperfeiçoamento das qualidades físicas, a incorporação de hábitos saudáveis e úteis à conservação da saúde e ao afastamento das doenças. O estudo do corpo humano no ensino primário estava em consonância com a finalidade precípua do ensino - a tornar os indivíduos úteis e aptos aos empreendimentos da vida e indicar-lhes a necessidade de constituição da família. Nessa perspectiva, os conhecimentos veiculados sobre o corpo humano se conectavam aos valores morais e cívicos da época. Assim, o currículo prescrito no ensino de ciências demarcava os limites do que poderia ser conhecido pelos estudantes, sobre a constituição e estruturas externas e internas de seus próprios corpos.

No ensino de ciências simultaneamente se acolheu e se erigiu um corpo padrão como ente abstrato, canônico, dissociado de qualquer pessoa - o corpo masculino. Os fenômenos corpóreos foram ensinados e aprendidos a partir e sobre uma perspectiva e antropocêntrica, androcêntrica, pois ao falar sobre o corpo e os fenômenos corpóreos, apenas se falava do homem. A mulher e os fenômenos biológicos relativos ao corpo feminino eram suprimidos e silenciados no currículo. O corpo feminino não existia de modo explicito no currículo da escola primária. Todavia, o currículo demarcava e enfatizava os papéis sociais e a conduta moral, incumbida às mulheres, precipuamente relativos ao trabalho doméstico, ao cuidar e a maternidade compulsória. O currículo não abordava as estruturas biológicas do corpo das mulheres, no entanto enfatizava lhes os papéis sociais, a conduta moral e o comportamento feminino socialmente desejado, vinculando-os aos atributos corpóreos femininos.

A interpretação de fenômenos biológicos, na produção da ciência, encontra-se impregnada pela cultura, pelo social e pelas demandas e interesses políticos de cada contexto histórico, que autorizam/ desautorizam certas interpretações do corpo humano e de suas partes. Portanto, além de sua inexorável dimensão biológica, o corpo humano, em suas camadas, em sua espessura - sistemas, órgãos, tecidos e células - é também uma produção social, cultural e consequentemente histórica, logo o palco de políticas simbólicas e o cenário de exercícios de poder.

\section{REFERÊNCIAS}

ACRE. Regulamento de Instrução Pública do Departamento do Território do Acre. José Lopes de Aguiar. Diretor do Departamento de Instrução Pública, 1930.

AUAD, D. Educação para a democracia e co-educação: apontamentos a partir da categoria gênero. Revista USP, São Paulo, s./v., n. 56, p. 136-143, dez./fev. 2003.

BIERNACKI, P.; WALDORF, D. Snowball sampling: problems and techniques of chain referral sampling. Sociological Methods \& Research, Thousand Oaks, v.10, n. 2, p. 141-163, nov. 1981

BOURDIEU, P. A dominação masculina. Rio de Janeiro: Bertrand Brasil, 2012.

CASTRO. C. O. Gestão Maria Angélica de Castro: apropriação das ideias sobre a escola nova no território federal do Acre (1946/1951). 2011, 239 f. Tese (Doutorado em Educação) - Faculdade de Educação, Universidade Federal de Minas Gerais, Belo Horizonte, 2011. 
ELIAS, N. Uma história dos costumes. Rio de Janeiro: Jorge Zahar, 1994.

FAUSTO-STERLING, A. Cuerpos sexuados. Barcelona: Melusina, 2006.

FOUCAULT, M. Vigiar e punir: nascimento da prisão. Petrópolis: Vozes, 1987.

GINELLI, G. História da Educação do Acre: período departamental 1904-1920. Livro 1. Rio Branco: SEE, 2008.

GIROUX, H. Atos impuros: a prática política dos estudos culturais. Porto Alegre: Artmed, 2003.

GOODSON, I. A construção social do currículo. Lisboa: Educa, 1997.

LAQUEUR, T. Inventando o sexo: corpo e gênero dos gregos a Freud. Rio de Janeiro: Relume Dumará, 2001.

LE GOFF, J.; TRUONG, N. Uma história do corpo na idade média. Rio de Janeiro: Civilização Brasileira, 2012.

LOURO, G. L.; FELIPE, J.; GOELLNER, S. V. (orgs.). Corpo, gênero e sexualidade: um debate contemporâneo na educação. Petrópolis: Vozes, 2012.

LIMA. E. M. Modos diferenciados na produção da escolarização primária no Acre Território: a organização do trabalho docente e dos saberes presentes na educação da infância acriana. In.: NASCIMENTO, L. M.; LIMA, E. M.; ALBUQUERQUE, L. B. A. (orgs.). Moderno/Contemporâneo: reflexões sobre a educação escolar. Curitiba: Appris, 2012.

MARTINELLO, P. A batalha da borracha na Segunda Guerra Mundial e suas conseqüências para o vale amazônico. Rio Branco: UFAC, 1988.

NOGUEIRA, A. R. Relatório do diretor de instrução pública. 1921, p. 2. In.: GINELLI, G. História da educação acreana. Rio Branco: UFAC/DE, 1982.

PERTIÑEZ, J.; LOMBARDI, M. História da prelazia do Acre e Purús. Ordem dos Servos de Maria. Rio Branco: OSM, s./d.

ROHDEN, F. A construção da diferença sexual na medicina. Cad. Saúde Pública, Rio de Janeiro, v. 19, suppl. 2, p. 201-212, 2003. 